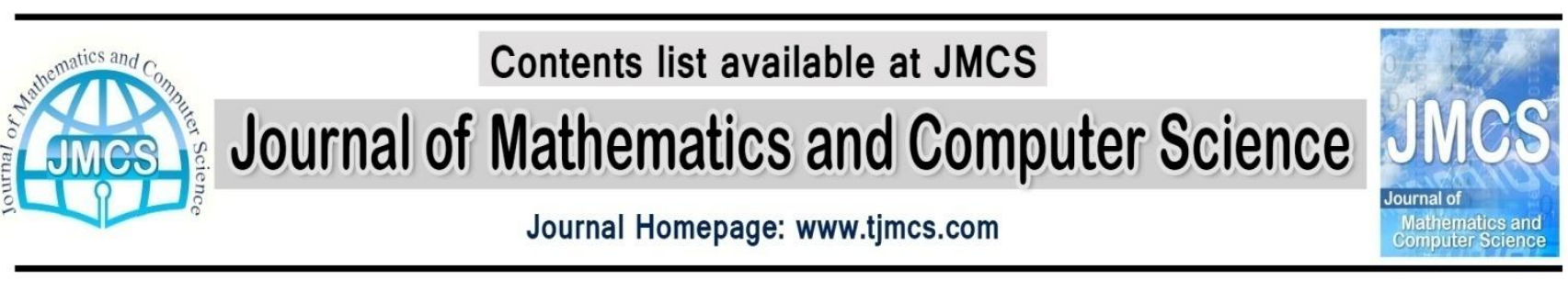

\title{
OPEC Oil Price Prediction Using ANFIS
}

\author{
Ehsan Lotfi ${ }^{1}$, M.R. Karimi ${ }^{2}$ \\ ${ }^{1}$ Department of Computer Engineering, Torbat-e-Jam Branch, Islamic Azad University, Torbat-e-Jam, Iran \\ ${ }^{2}$ Department of Accounting, Torbat-e-Jam Branch, Islamic Azad University, Torbat-e-Jam, Iran \\ elotfi@bitools.ir,esilotf@gmail.com
}

Article history:

Received January 2014

Accepted April 2014

Available online May 2014

\begin{abstract}
In this paper adaptive neuro-fuzzy inference system (ANFIS) is developed to predict the oil prices of the organization of petroleum exporting countries (OPEC). The novel aspect of the proposed model is the proposed features set fed the ANFIS. In the numerical studies, the proposed method is tested to modeling OPEC oil time series as a case study. According to the comparative results, ANFIS with proposed variables set shows higher accuracy than conventional neural networks in oil price prediction.
\end{abstract}

Keywords: Artificial neural network; Fuzzy; Oil; Forecasting.

\section{Introduction}

Recently a scientific issue, related to the oil price prediction, has been considered by artificial intelligence (AI) researchers and economic analyzers (Knetsch 2007; Shafiee \& Topal 2010; Shin et al. 2012). Generally there are two approaches to this issue, including mathematical models and Artificial Intelligence (AI) methods. Mathematical models include VAR (Alquist and Kilian 2010), kalman filter (Bhar and Lee 2011) ARMA (Karia et al. 2013), ARCH and GARCH etc. ( Morana, 2001; Sadorsky 2002; Yaziz et al., 2011; Baumeiste \& Kilian 2012; Deepika et al. 2012; Gibson and Schwartz 1990). And Al methods consist of learning based methods such as Artificial Neural Network (ANN; Lotfi and Navidi 2012; Mehdi Sotoudeh and Elahe Farshad 2012; Ali ghezelbash 2012; Hamze Ravaee et al. 2012; Lachtermacher and Fuller 1995; Moshiri, \& Cameron 2000; Haidar and Kulkarni 2008; Malliaris and Malliaris 2009, 2013; Anand et al., 2010; Mustaffa and Yusof, 2011; Mingming, 2012; Wang and Pan 2012; Parisi et al. 2008; Khashei et al. 2009) and Adaptive Neuro-Fuzzy Inference Systems (ANFIS; Atsalakis, 2012; He et al., 2012; Makridou et al. 2013). Al methods learn behavior by observing the previous values and predict the future values. The learning based methods are more accurate in economic time series prediction and among AI methods, ANFIS can show better results. Recently, Chen et al. (2014) show ANN is a better predictor that ARIMA model for forecasting gold price and Yazdani et 
al. (2012) show that ANFIS is the more appropriate than mathematical models and ANN. They have utilized CAM (cosine amplitude method; Yazdani et al. 2012) method to identify the most sensitive factors affecting gold price. CAM is not suitable for sensitivity analysis of economic time series, because it does not include behavioral similarities of time series. This paper aims to apply ANFIS in OPEC oil price time series prediction. ANFIS successfully learn the behavior and can be used for prediction and estimation and we believe that because high accuracy, it can be applied to find the sensitivity of economic parameters. Here we apply ANFIS for prediction of non-stationary chaotic economic time series of oil as a case study. The proposed model is general and can be applied in various economy based application domains such as product cost estimation (Smith \& Mason 1997; Liu 2010), stock price prediction (Ince and Trafalis 2007, 2008; Thawornwong, S., Enke and Dagli 2003), exchange rate detection (Sarantis \& Stewart, 1995; Akram 2004; Knowles et al. 2005; Alvarez-Diaz \& Alvarez 2007; Dunis et al. 2010; Amirhosseini \& Behbahani 2011; Ebrahimpour et al. 2011), inflation forecasting (Monteforte and Moretti 2013, Choudhary \& Haider 2012), forecasting different commodity prices (Chinn and Coibion 2013) as well as gas consumption and various demand functions estimation (Darbellay \& Slama 2000; Gorucu 2004; Çunkaş \& Altun2010; Azadeh et al. 2010).

The organization of the paper is as follows: ANFIS based modeling is presented in Section 1.1. Oil price prediction, is presented in Section 2. The method is evaluated in the Section 3 and conclusions are made in Section 4.

\subsection{ANFIS based modeling}

ANFIS is a Neuro-Fuzzy approach introduced by Jang (Jang et al. 1997, 1993), explored by Takagi and Sugeno (1985) and utilized in various control applications, prediction and inference. ANFIS is a fuzzy inference system that trains their learning parameters in ANN architecture. A fuzzy system transmits expert knowledge expressed by linguistic rules into a mathematical framework and ANFIS adjusts these rules using ANN architecture. In other words, ANFIS is a solution that combines fuzzy systems and ANN and uses the advantages of them where the fuzzy rules and membership functions are generated automatically.

In Sugeno-type ANFIS, the rules can be obtained by subtractive clustering (subclust). The subtractive clustering (Chiu 1994; Yager and Filev 1994) is used to determine the number of rules and antecedent membership functions. Also the linear least squares estimation is applied to determine each rule's consequent equations. This method is implemented in Matlab function "subclust" and applied in function "genfis2". The subclust uses a cluster center's range of influence (radii) in each of the data dimensions. Small ranges generally results a few large clusters and big ranges results many little clusters. These ranges can be tuned separately and manually for each problem. Here, membership functions are Gaussian (gaussmf), output membership function is linear and a manual optimum radius is proposed for each case study. In inference method, AND is prob, OR is probor, implication is min and aggregation is max and defuzzification method is weighted average (wtaver).

\section{Oil Price Prediction}

Oil bear great importance on economic markets and their prices play pivotal role in the global economy. These prices can be considered as economic time series showing non-stationary, non-linear chaotic behavior and high uncertainty (Elder and Serletis 2010). Recently various predictor models have been utilized by researchers and analysts to predict oil prices. An accurate predictor can help to foresee the circumstances of trends in the future (Yazdani-Chamzini et al. 2012) and provide the useful information 
for customers, suppliers, politicians and generally for stakeholder to fulfill the appropriate strategies in order to prevent or mitigate risks (Yazdani-Chamzini et al. 2012). These prices are very difficult to forecast (Coimbra and Esteves 2004). So in the literature, the predictors have been investigated in order to find the best predictor. As mentioned above, ANFIS can show better result in prediction and we apply it as follows:

At the first, Let us list the affecting parameters on the oil prices. As mentioned in the published papers, there are various parameters that affect oil prices such as OPEC (The Organization of Petroleum Exporting Countries) production level, inflation rate, interest rate, gold and silver prices, global economy as well as imports of major purchaser countries such as USA (Hamilton 2009; Nashawi et al. 2010). These parameters can be considered as inputs of ASFIS where its output is oil price. The list of parameters considered here are shown in Table 1. These parameters are used as shown in Fig. 1. Fig. 1 shows the ANFIS based oil price predictor that has two sets of input variables: First set is the parameters under consideration presented in Table 1 and the second set is the oil prices of three previous periods including $O p_{i-1}, O p_{i-2}$, and $O p_{i-3}$. The output of ANFIS is the predicted oil price for current period $i\left(O p_{i}\right)$. The proposed input variables for ANFIS model is a novel aspect presented here. Published works such as (Yazdani et al. 2012) have not considered previous values of time series beside other parameters.

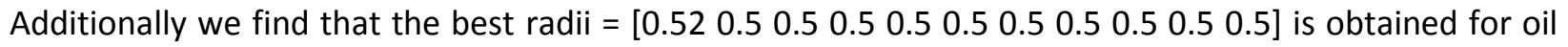
price prediction.

Table 1. Economic variables under consideration for prediction

\begin{tabular}{|c|c|c|c|c|}
\hline & Input Variable & Unit & Symbol & Source \\
\hline 1) & US Inflation rate & - & Inf & $\underline{\text { http://inflationdata.com }}$ \\
\hline 2) & Interest rate & - & Int & $\underline{\text { http://www.EconStats.com }}$ \\
\hline & OPEC oil & Thousand & & \\
3) & production level & Barrels & Opl & $\underline{\text { http://tonto.eia.gov }}$ \\
\hline 4) & Gold Price & \$/ounce & Gp & $\underline{\text { http://www.gold.org }}$ \\
\hline 5) & Silver Price & \$/ounce & Sil & $\underline{\text { https://www.silverinstitute.org }}$ \\
\hline 6) & Market Index & \$ & Dji & $\underline{\text { http://finance.yahoo.com }}$ \\
\hline 7) & U.S. Dollar Index & - & Din & $\underline{\text { http://research.stlouisfed.org }}$ \\
\hline 8) & Oil price (USA F.O.B. & Dollars & Op & $\underline{\text { http://tonto.eia.gov }}$ \\
& cost of OPEC) & per Barrel & & \\
\hline
\end{tabular}




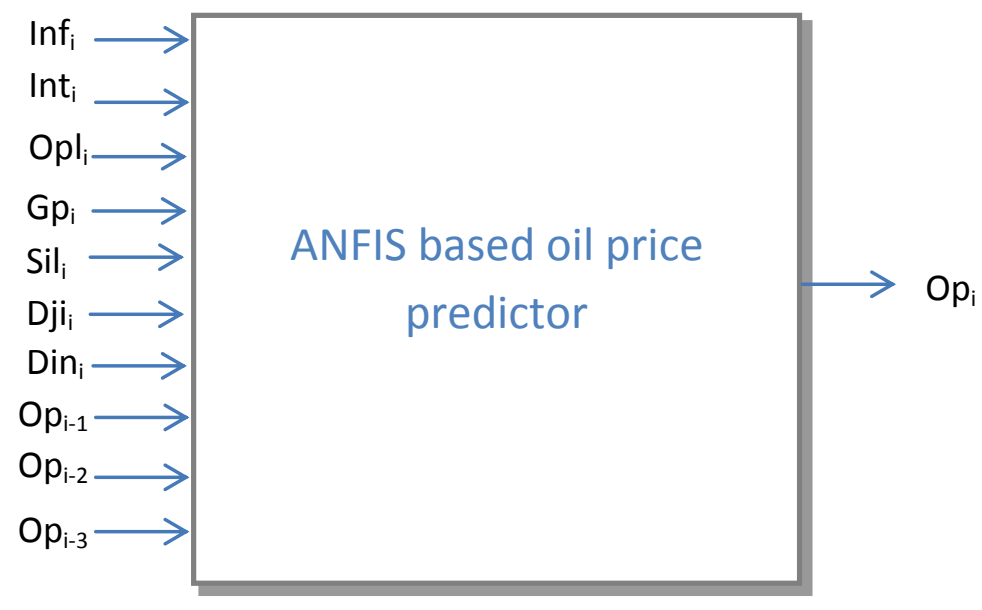

Fig. 1. Inputs and output of ANFIS as oil price predictor

\section{Numerical results in price prediction}

A 136 monthly samples data set from Sep. 2001 to Dec. 2012 has been used for prediction. The data sets are accessible from sources presented in Table 1. The monthly data from Sep. 2001 to Nov. 2009 are used for ANFIS training, from Dec. 2010 to Dec. 2012 are used for testing and the remaining set is the validation set. In experimental studies, the measures are the size of error, the root mean squared error (RMSE) and the correlation coefficient (COR).

Fig. 2 presents the oil prediction results and the related error obtained from ANFIS. In Fig. 2, the training region is between months [Sep-2001 Nov-2009]and months [Dec-2010 Dec-2012] are for the testing where the prediction results are evaluated. The validation set is used to find the best radii that is [0.52 0.50 .50 .50 .50 .50 .50 .50 .50 .50 .5 . As illustrated in Table 2, in Op prediction, a correlation COR = 0.98470 and test RMSE $=22.3565$ are obtained. We use this dataset to do some experiments to examine performance of ANFIS and compare it with performance of an ANN model. We consider LevenbergMarque (LM) learning based ANN with at least five different structures (single layer with 5, 10, 15, 20, and 25 neurons in the hidden layer). For each network, experiments are repeated 10 times on validation set. The obtained validation set RMSE for 5, 10, 15, 20, and 25 hidden neurons are $6.240000716 \pm$ $4.682317126,8.015831731 \pm 3.742401937,9.181441105 \pm 3.305491527,7.743900664 \pm 2.798479512$ and $16.06593922 \pm 5.027978399$ respectively. Thus the best ANN architecture for oil price forecasting is 10-5-1 (10 input features, 5 hidden neurons and 1 output.) Table 2 shows the comparative results according to the Student-t test with $95 \%$ confidence. 

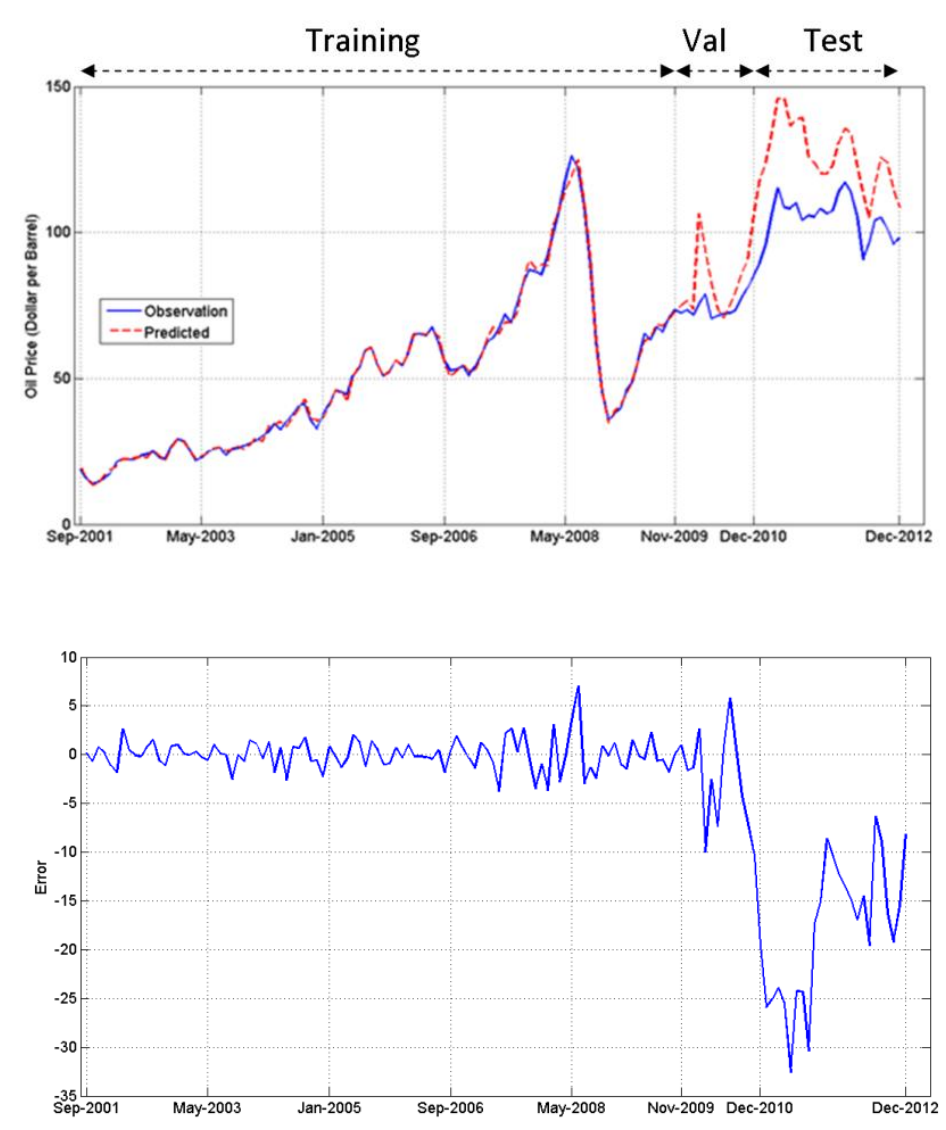

Fig. 2.Predicted oil prices (top) and related error (bottom) from start point inSep.2001 obtained usingANFIS with best input set and proposed radii.

Fig. 2 presents the results of prediction from the start point at Dec-2001. As illustrated in Fig. 2, last 24 months are used for testing the system. The predicted curve illustrated in Figs. 4, is divided into the three segments; the first is the training region that is between months [Sep-2001 Nov-2009]. And the second is the validating region that is between months (Nov-2009 Dec-2010) and the thirds is testing region where the prediction results are validated and it's between [Dec-2010 Dec-2012].

Table 2 Comparative results of price prediction between ANN and ANFIS with proposed variables set

\begin{tabular}{|c|c|l|l|l|}
\hline Time series & Model & TrainingSet RMSE & TestSet RMSE & Best Correlation \\
\hline \multirow{3}{*}{ Oil } & ANFIS & $1.5810 \pm 0$ & $22.3565 \pm 0$ & 0.98470 \\
\cline { 2 - 5 } & $\begin{array}{c}\text { Optimum } \\
\text { ANN }\end{array}$ & $7.355527 \pm 4.648605$ & $20.3629 \pm 14.61734$ & 0.94264 \\
\hline \hline
\end{tabular}




\section{Conclusions}

ANFIS is an appropriate predictor for OPEC oil price prediction. In contrast to the mathematical model such as ARIMA, ANFIS approach learns pattern-target samples and applies well to adaptive economic problems. The proposed ANFIS with a novel input features set is utilized here to predict the oil prices and considers various economic parameters such as inflation rate, interest rate, OPEC oil production level, silver price, market index and U.S. dollar index.Numerical studies present the following conclusion that ANFIS with the proposed input variables shows higher performance than neural networks in price modeling and can be used in various economic application domains.

\section{References}

1. Akram, Q. F. (2004). Oil prices and exchange rates: Norwegian evidence. the econometrics Journal, $7(2), 476-504$.

2. Ali ghezelbash, Predicting Changes in Stock Index and Gold Prices to Neural Network Approach (2012). Journal of mathematics and computer Science. 4(2), $227-236$.

3. Alquist, R., \& Kilian, L. (2010). What do we learn from the price of crude oil futures?. Journal of Applied Econometrics, 25(4), 539-573.

4. Alvarez-Diaz, M., \& Alvarez, A. (2007). Forecasting exchange rates using an evolutionary neural network. Applied Financial Economics Letters, 3(1), 5-9.

5. Amirhosseini, Z., \& Behbahani, S. M. (2011). Prediction of Expected Rate of Return in Tehran Stock Exchange. In Proceedings of the World Congress on Engineering (Vol. 1).

6. Anand A., Gulenc, D., Lartigue, J., (2010), Forecasting Petroleum Prices. Available from: http://mysbfiles.stonybrook.edu/ abanand/Econometrics Project.pdf

7. Atsalakis, G.S., (2012), Forecasting the Prices of Credit Default Swaps of Greece by a Neuro-fuzzy Technique. Technical University of Crete.

8. Azadeh, A., Asadzadeh, S. M., \& Ghanbari, A. (2010). An adaptive network-based fuzzy inference system for short-term natural gas demand estimation: uncertain and complex environments. Energy Policy, 38(3), 1529-1536.

9. Baumeister, C., \& Kilian, L. (2012). Real-time forecasts of the real price of oil. Journal of Business \& Economic Statistics, 30(2), 326-336.

10. Bhar, R., \& Lee, D. (2011). Time-varying market price of risk in the crude oil futures market. Journal of Futures Markets, 31(8), 779-807.

11. Chen, H. H., Chen, M., \& Chiu, C. C. (2013). The Integration of Artificial Neural Networks and Text Mining to Forecast Gold Futures Prices. Communications in Statistics-Simulation and Computation, DOI:10.1080/03610918.2013.786780 
12. Choudhary, M. A., \& Haider, A. (2012). Neural network models for inflation forecasting: an appraisal. Applied Economics, 44(20), 2631-2635.

13. Chinn, M. D., \& Coibion, O. (2013). The predictive content of commodity futures. Journal of Futures Markets, 000-000.

14. Chiu, S., (1994). Fuzzy Model Identification Based on Cluster Estimation, Journal of Intelligent \& Fuzzy Systems, Vol. 2, No. 3, Sept. 1994

15. Coimbra, C., \& Esteves, P. S. (2004). Oil price assumptions in macroeconomic forecasts: should we follow futures market expectations?. OPEC review, 28(2), 87-106.

16. Conraria, A.L. and Wen, Y., (2011), OPEC's Oil Exporting Strategy and Macroeconomic (in) stability. Working Papers 2011-013. Available from: http://hdl.handle.net/1822/11993

17. Çunkaş, M., \& Altun, A. A. (2010). Long Term Electricity Demand Forecasting in Turkey Using Artificial Neural Networks. Energy Sources, Part B: Economics, Planning, and Policy, 5(3), 279-289.

18. Darbellay, G. A., \& Slama, M. (2000). Forecasting the short-term demand for electricity: Do neural networks stand a better chance?. International Journal of Forecasting, 16(1), 71-83.

19. Deepika, M. G., Nambiar, G., \& Rajkumar, M. (2012). Forecasting Price and Analysing Factors influencing the Price of Gold using ARIMA Model and Multiple Regression Analysis.

20. Dejuán, Ó., López, L. A., Tobarra, M. Á., \& Zafrilla, J. (2013). A POST-KEYNESIAN AGE MODEL TO FORECAST ENERGY DEMAND IN SPAIN. Economic Systems Research, (ahead-of-print), 1-20.

21. Dunis, C. L., Laws, J., \& Sermpinis, G. (2010). Modelling and trading the EUR/USD exchange rate at the ECB fixing. The European Journal of Finance, 16(6), 541-560.

22. Ebrahimpour, R., Nikoo, H., Masoudnia, S., Yousefi, M. R., \& Ghaemi, M. S. (2011). Mixture of MLPexperts for trend forecasting of time series: a case study of the Tehran stock exchange. International Journal of Forecasting, 27(3), 804-816.

23. Elder, J., \& Serletis, A. (2010). Oil price uncertainty. Journal of Money, Credit and Banking, 42(6), 1137-1159.

24. George, S., Tsakalaki, K.I., (2012), Forecasting the Prices of Credit Default Swaps of Greece by a Neuro-fuzzy Technique. Technical University of Crete. Available from: http://www.fel.tuc.gr/Working\%20papers/2012_03.pdf

25. Gibson, R., \& Schwartz, E. S. (1990). Stochastic convenience yield and the pricing of oil contingent claims. The Journal of Finance, 45(3), 959-976.

26. Gorucu, F. B. (2004). Artificial neural network modeling for forecasting gas consumption. Energy Sources, 26(3), 299-307. 
27. Hamilton J. D., (2008), Understanding Crude Oil Prices. Policy and Economics, University of California Energy Institute, UC Berkeley.

28. Hamze Ravaee, Saeid Farahat, Faramarz Sarhaddi, (2012). Artificial Neural Network Based Model of Photovoltaic Thermal (PVT) Collector. Journal of mathematics and computer Science, 4(3), 411 417.

29. Haidar, I., Kulkarni, S., Pan, H., (2008), Forecasting Model for Crude Oil Prices Based on Artificial Neural Networks. IEEE ISSNIP, 15-18 Dec., pp: $103-108$.

30. He, S., Zou, Y., Quan, D., (2012), Application of RBF Neural Network and ANFIS on the Prediction of Corrosion Rate of Pipeline Steel in Soil. Recent Advances in Computer Science, 124: 639-644.

31. Ince, H., \& Trafalis, T. B. (2008). Short term forecasting with support vector machines and application to stock price prediction. International Journal of General Systems, 37(6), 677-687.

32. Ince, H., \& Trafalis, T. B. (2007). Kernel principal component analysis and support vector machines for stock price prediction. IIE Transactions, 39(6), 629-637.

33. Jang, J. S. (1993). ANFIS: adaptive-network-based fuzzy inference system. Systems, Man and Cybernetics, IEEE Transactions on, 23(3), 665-685.

34. Jang, J. S. R. (1997). ANFIS architecture. Neuro-Fuzzy and Soft Computing, John Wiley \& Sons Inc.

35. Karia, A. A., Bujang, I., \& Ahmad, I. (2013). Fractionally integrated ARMA for crude palm oil prices prediction: case of potentially overdifference. Journal of Applied Statistics, 40(12), 2735-2748.

36. Khashei, M., Bijari, M., \& Raissi Ardali, G. A. (2009). Improvement of auto-regressive integrated moving average models using fuzzy logic and artificial neural networks (ANNs). Neurocomputing, 72(4), 956-967.

37. Knetsch, T. A. (2007). Forecasting the price of crude oil via convenience yield predictions. Journal of Forecasting, 26(7), 527-549.

38. Knowles, A., Hussein, A., Deredy, W., Lisboa, P., \& Dunis, C. L. (2005). Higher-order neural networks with Bayesian confidence measure for prediction of EUR/USD exchange rate. Artificial Higher Order Neural networks for Economics and Business, ed. by M. Zhang (Idea Group, Hershey, 2009), 48-59.

39. Kilian, L., \& Vigfusson, R. J. (2013). Do oil prices help forecast us real gdp? the role of nonlinearities and asymmetries. Journal of Business \& Economic Statistics, 31(1), 78-93.

40. Lachtermacher, G., \& Fuller, J. D. (1995). Back propagation in time-series forecasting. Journal of Forecasting, 14(4), 381-393. 
41. Liu, H. (2010). Cost estimation and sensitivity analysis on cost factors: a case study on Taylor Kriging, regression and artificial neural networks. The Engineering Economist, 55(3), 201-224.

42. Lotfi, E., \& Navidi, H., (2012). A Decision Support System for OPEC Oil Production Level based on Game Theory and ANN. Advances in Computational Mathematics and its Applications. Vol. 2, No. 1, 2012.

43. Luying Hao \& Ruizhi Wu, (2012), Journal of Comparative Literature and Culture (JCLC), Vol. 1, No. 4, pp. 67-73.

44. Malliaris, A. G., \& Malliaris, M. (2009, June). Time series and neural networks comparison on gold, oil and the euro. In Neural Networks, 2009. IJCNN 2009. International Joint Conference on (pp. 1961-1967). IEEE.

45. Malliaris, A. G., \& Malliaris, M. (2013). Are oil, gold and the euro inter-related? Time series and neural network analysis. Review of Quantitative Finance and Accounting, 40(1), 1-14.

46. Mehdi Sotoudeh, Elahe Farshad, (2012). Application of neural network for forecasting gas price in America. Journal of mathematics and computer Science, 4(2), 2016-226.

47. Monteforte, L., \& Moretti, G. (2013). Real-Time Forecasts of Inflation: The Role of Financial Variables. Journal of Forecasting, 32(1), 51-61.

48. Moshiri, S., \& Cameron, N. (2000). Neural Network Versus Econometric Models in Forecasting Ination. Journal of Forecasting, 19, 201-217.

49. Morana, C., (2001), A semi parametric approach to short term oil price forecasting. Energy Economics 23 325-388

50. Malliaris, A.G., Malliaris, M., (2009), Time Series and Neural Networks Comparison on Gold, Oil and the Euro. Proceedings of International Joint Conference on Neural Networks, Atlanta, Georgia, USA.

51. Makridou, G., Atsalakis, G. S., Zopounidis, C., \& Andriosopoulos, K. (2013). Gold price forecasting with a neuro-fuzzy-based inference system. International Journal of Financial Engineering and Risk Management, 1(1), 35-54.

52. Mingming, T., (2012), A Multiple Adaptive Wavelet Recurrent Neural Network Model to Analyze Crude Oil Prices. Journal of Economics and Business, 64(4): 275-286.

53. Morana, C., (2001), A Semi Parametric Approach to Short Term Oil Price Forecasting. Energy Economics, 23:325-388.

54. Mustaffa, Z., Yusof, Y., (2011), Optimizing LSSVM Using ABC for Non-Volatile Financial Prediction. Australian Journal of Basic and Applied Sciences. 5(11): 549-556. 
55. Nashawi S, Malallah A, Al-Bisharah M, (2010), Forecasting World Crude Oil Production Using Multicyclic Hubbert Model. Energy Fuels, 24:1788-1800.

56. Parisi, A., Parisi, F., \& Díaz, D. (2008). Forecasting gold price changes: Rolling and recursive neural network models. Journal of Multinational financial management, 18(5), 477-487.

57. Ross, T. J. 2004. Fuzzy Logic with Engineering Applications. Second edition. John Wiley \& Sons Ltd.

58. Shafiee, S., \& Topal, E. (2010). An overview of global gold market and gold price forecasting. Resources Policy, 35(3), 178-189.

59. Sadorsky, P., (2002), Time-Varying Risk Premiums in Petroleum Futures Prices. Energy Economics, 24:539-556.

60. Sarantis, N., \& Stewart, C. (1995). Structural, VAR and BVAR models of exchange rate determination: a comparison of their forecasting performance. Journal of Forecasting, 14(3), 201215.

61. Schmidbauer H, Rösch A, (2012), OPEC News Announcements: Effects on Oil Price Expectation and Volatility. doi:10.1016/j.eneco.2012.01.006

62. Shin, H., Hou, T., Park, K., Park, C. K., \& Choi, S. (2012). Prediction of movement direction in crude oil prices based on semi-supervised learning. Decision Support Systems.

63. Smith, A. E., \& Mason, A. K. (1997). Cost estimation predictive modeling: Regression versus neural network. The Engineering Economist, 42(2), 137-161.

64. Suganthi, L., \& Samuel, A. A. (2012). Energy models for demand forecasting-A review. Renewable and Sustainable Energy Reviews, 16(2), 1223-1240.

65. Takagi, T., \& Sugeno, M. (1985). Fuzzy identification of systems and its applications to modeling and control. Systems, Man and Cybernetics, IEEE Transactions on, (1), 116-132.

66. Thawornwong, S., Enke, D., \& Dagli, C. (2003). Neural networks as a decision maker for stock trading: a technical analysis approach. International Journal of Smart Engineering System Design, 5(4), 313-325.

67. WangJ., Pan H., (2012), Forecasting Crude Oil Price and Stock Price by Jump Stochastic Time Effective, Neural Network Model, Journal of Applied Mathematics. doi:10.1155/2012/646475.

68. Yazdani-Chamzini, A., Yakhchali, S. H., Volungevičienè, D., \& Zavadskas, E. K. (2012). Forecasting gold price changes by using adaptive network fuzzy inference system. Journal of Business Economics and Management, 13(5), 994-1010. 
69. Yaziz, S.R., Ahmad, M.H., Nian, L.C., Muhammad, N., (2011), A Comparative Study on Box-Jenkins and Garch Models in Forecasting Crude Oil Prices. Journal of Applied Sciences, 11: 1129-1135.

70. Yager, R. and D. Filev, (1994). Generation of Fuzzy Rules by Mountain Clustering, Journal of Intelligent \& Fuzzy Systems, Vol. 2, No. 3, pp. 209-219. 